Available online on 24.01.2018 at http://jddtonline.info
Journal Of Drug Delivery and Therapeutics
Open Access to Pharmaceutical and Medical Research
O2011-18, publisher and licensee JDDT, This is an Open Access article which permits unrestricted
non-commercial use, provided the original work is properly cited

Open $\odot$ Access

Research Article

\title{
Protective EFFECT OF A TRADITIONAL MEDICINE, RUTIN, AGAINST LIPOPOLYSACCHARIDE-INDUCED ENDOTOXEMIA IN
}

\section{MICE}

Lanan Wassy Soromou, Morlaye Kindia Sylla, Mohamed Keyra, Youssouf Sidime

Institut supérieur des Sciences et de Médecine Vétérinaire (ISSMV) de Dalaba, République de Guinée

\section{ABSTRACT}

Lipopolysaccharide (LPS) is a main causative agent of septic shock. In this study we investigated the possible effects of Rutin (RT) against LPS-induced endotoxemia model in vivo to determine whether RT could rescue mice from ensuing death after their exposure to LPS. To further understand the role of RT, the responses of cytokines were also assessed in serum isolated from blood collected at 0 , $1.5,3,6$, and $12 \mathrm{~h}$ after LPS administration of the mice. In the study, RT showed suppressive effects on TNF- $\alpha$, IL- 6 , and IL-1 $\beta$ production by LPS- challenged mice. Furthermore, RT protected mice by improving host survival against LPS challenge. The present findings reinforce the potential of RT, a natural compound as drug candidate for prevention of sepsis progression.

Keywords: Rutin, lipopolysaccharide, cytokine, sepsis, mice.

Article Info: Received 13 Dec, 2017; Review Completed 23 Jan, 2018; Accepted 24 Jan, 2018; Available online 24 Jan, 2018

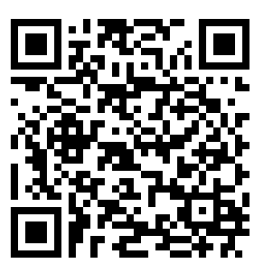

Cite this article as:

Soromou LW, Sylla MK, Keyra M, Sidime Y, Protective effect of a traditional medicine, rutin, against lipopolysaccharide-induced endotoxemia in mice, Journal of Drug Delivery and Therapeutics. 2018; 8(1):108-113

DOI: http://dx.doi.org/10.22270/jddt.v8i1.1675

\section{${ }^{*}$ Address for Correspondence}

Dr. Lanan Wassy Soromou, Institute of Sciences and Veterinary Medicine (ISSMV) of Dalaba, P.O Box 09, Republic of Guinea. (T) 00224 620212378 (E) lananwassy@ gmail.com

\section{Acknowledgements}

We are grateful for financial supports from Institute of Sciences and Veterinary Medicine (ISSMV) of Dalaba, Republic of Guinea. 


\section{INTRODUCTION}

Inflammation is a localized protective response elicited by injury or destruction of tissues that serves to destroy, dilute, or sequester the injurious agent and injured tissue. Sepsis is considered a systemic inflammatory disorder and a serious clinical problem with a high mortality. The acute-phase response is a major pathophysiological phenomenon that accompanies inflammation and is associated with increased activity of pro-inflammatory cytokines ${ }^{1}$. Bacterial LPS, a constituent of the cell wall of Gram-negative bacteria, is a major causative agent of septic shock. In experimental animals, LPS challenge leads to pathophysiological changes similar to the human septic shock syndrome. The presence of apoptotic cells during monocyte activation with LPS decreases secretion of the proinflammatory cytokines TNF- $\alpha$, IL-1, and IL-12 2 . Major cytokines that participate in the inflammatory response after LPS administration include tumor necrosis factor (TNF)- $\alpha$, as well as interleukin (IL)-1, -2, -6, and -8 ${ }^{3}$. The TLR4 family plays a central role in activation of innate immune system. LPS is thought to bind directly to TLR4, and it initiates the transmembrane signaling via an adaptor protein MyD88, leads to activation of NF- KB, and induces a number of inflammatory mediators ${ }^{4}$.

Rutin (RT) (figure 1), a citrus flavonoid found in a wide variety of plants including citrus fruit ${ }^{5}$, buckwheat ${ }^{6}$ is known to possess antioxidant properties ${ }^{7}$ by effectively reducing ferryl intermediate back to ferric $\mathrm{Hb}$ at physiological $\mathrm{pH}$. It exhibited more protective effect on $\mathrm{H}_{2} \mathrm{O}_{2}$-induced $\mathrm{Hb}$ oxidation ${ }^{8}$. Furthermore, rutin increased skin elasticity and decreased the length, area and number of wrinkles ${ }^{7}$. A number of studies have shown that RT relieves swelling, aching, and pain from varicose veins. Because RT strengthens arteries and veins, it is also used to help treat hemorrhoids, internal bleeding, and to help prevent hemorrhagic strokes. Scientists found that RT inhibited the enzyme Coll2-1, a marker for osteoarthritis ${ }^{9}$. Its use is advantageous over other flavonoids as it is a nontoxic and nonoxidizable molecule. Although research has shown its multispectrum pharmacological benefits for the treatment of various chronic diseases such as cancer, diabetes, hypertension and hypercholesterolemia ${ }^{10}$, little progress was done about its antiinflammatory effects on septic shock. It has been known that any means to regulate an excessive systemic inflammatory response would be a promising and beneficial strategy leading to a mitigation of endotoxic sepsis. Therefore, in this study, we evaluated the effects of RT against lethal endotoxemia in mice.<smiles>CCCCOc1c(-c2ccc(O)c(O)c2)oc2cc(O)cc(O)c2c1=O</smiles>

Figure 1: The chemical structure of Rutin

\section{MATERIALS AND METHODS}

\section{Chemical and reagents}

Rutin (purity 98.7\%) was purchased from the Sichuan Tongtai Botanical Chemical Industry Co., Ltd. Dimethyl sulfoxide (DMSO) and lipopolysaccharide (LPS, Escherichia coli 055:B5) were purchased from Sigma Chemical Co. (San Diego, CA, USA). (TNF)- $\alpha$, IL-1 $\beta$, and IL-6 ELISA kits were purchased from Biolegend (San Diego, CA).

\subsection{Animals}

$\mathrm{BALB} / \mathrm{c}$ male mice, 8 weeks old and weighing approximately 18 to $20 \mathrm{~g}$, were maintained at an animal facility under pathogen free conditions. The mice were fed a standard diet and water ad libitum and housed in microisolator cages under standard conditions (temperature: $24 \pm 1{ }^{\circ} \mathrm{C}$, relative humidity: 40\%-80\%). The mice were allowed to adapt themselves to their environment for 2-3 days before experimentation.

\section{Induction of shock and treatment regimen}

To select a suitable concentration of LPS for inducing shock, 48 mice were divided into four groups ( $\mathrm{n}=12$ /group) and challenged with LPS $(5-40 \mathrm{mg} / \mathrm{kg}$ ) via a single intraperitoneal (IP) injection. The mice were observed for mortality twice a day for 7 days, and survival rates were recorded.

Mice were treated with RT at different doses $(60,80$ or $100 \mathrm{mg} / \mathrm{kg}$ ), or vehicle (5\% of DMSO in saline), by the intraperitoneal (i.p.) route. One hour later, animals were challenged with LPS $(20 \mathrm{mg} / \mathrm{kg})$. The mice were randomly divided into five groups, i.e. control (vehicle), 
LPS $(20 \mathrm{mg} / \mathrm{kg})$ only, and RT $(60,80$, or $100 \mathrm{mg} / \mathrm{kg})+$ LPS.

\section{Measurement of cytokines concentrations}

At $0,1.5,3,6$, and $12 \mathrm{~h}$ after administration of the LPS, blood was recovered from the tail vein of each mouse and serum isolated; the serum was stored at $-70^{\circ} \mathrm{C}$. TNF- $\alpha$, IL-6, and IL-1 concentrations in serum samples were determined by enzyme-linked immunosorbent assay (ELISA), using the DuoSet kit from R\&D Systems (Minneapolis, MN).

\section{Statistical analysis}

Results are presented as means \pm SEM. Differences between mean values of normally distributed data were assessed with one-way ANOVA (Dunnett's t-test) and two-tailed Student's t-test. Statistical significance was accepted at $P<0.05$ or $P<0.01$.

\section{RESULTS}

\section{Effect of RT on LPS-induced mortality}

To evaluate the protective relevance of RT, we examined its effect on LPS-induced mortality in mice. After LPS challenge, mice showed signs of severe sepsis such as decreased activity, conjunctivitis, diarrhea, lethargy, piloerection, huddling, etc. Overall, mice that were injected with ip $40 \mathrm{mg} / \mathrm{kg}$ LPS survived until 12 hours. However, in groups of mice given 5, 10, or $20 \mathrm{mg} \mathrm{LPS} / \mathrm{kg}$, the mortality rates were, respectively, 5, 15, and $78 \%$ (Figure 2). Therefore, the concentration of $20 \mathrm{mg} \mathrm{LPS} / \mathrm{kg}$ was chosen as a lethal dose that induced septic shock. In the subsequent experiments here, mice were injected with the $20 \mathrm{mg}$ LPS $/ \mathrm{kg}$.

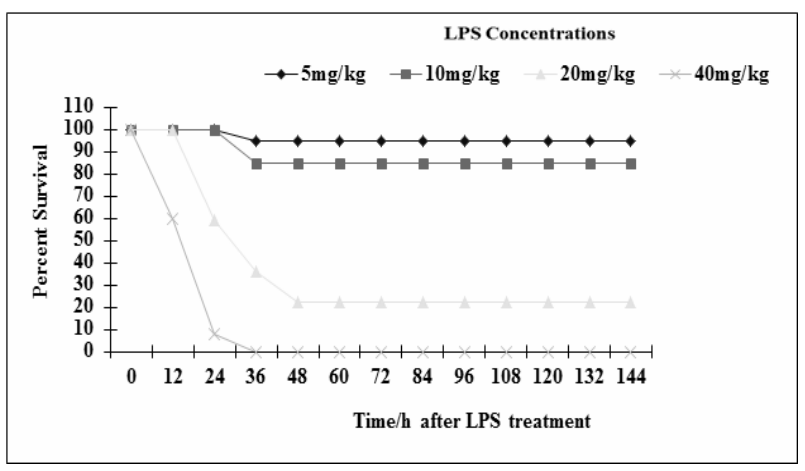

Figure 2: Effects of different doses of LPS in a mouse model of sepsis. The mice were divided into four groups ( $n=12 /$ group) and challenged with LPS (5-40 mg/kg) via a single intraperitoneal (IP) injection. The mice were observed for mortality twice a day for 7 days, and survival rates were recorded.

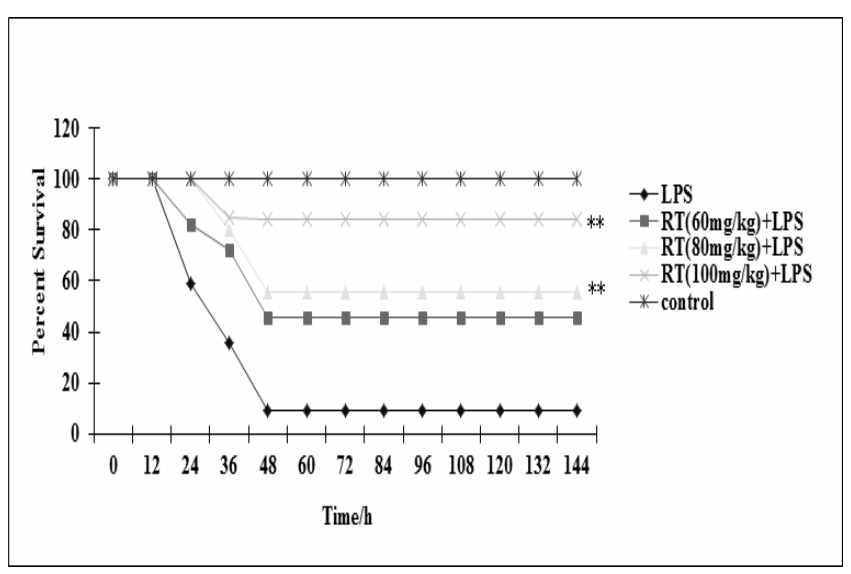

Figure 3. Effect of administration of Rutin (RT) on LPS-induced sepsis in mice. Mice were divided into five groups (control, LPS (20 mg/kg) only, and LPS (20 mg/kg) +3 treatment groups of RT) $(n=12 /$ group $) . * * p<0.01$ versus LPS-only group.

The pathophysiology of sepsis is supposed to be associated with a devastating or excessive host response involving dysregulated inflammation. Septic shock induced organ hypoperfusion, which progresses to multiple organ dysfunctions; this is clinically characterized by liver, pulmonary, cardiovascular, renal, and gastrointestinal dysfunction ${ }^{11}$. To assess the potential effect of RT against endotoxin-mediated mortality, its effect on mortality in mice with lethal endotoxemia was monitored. As shown in Figure 3, pre-treatment with RT significantly reduced LPS-induced mortality in mice. Taking the lower dose of RT $(60 \mathrm{mg} / \mathrm{kg})$ showed 46 percent protection. However, the doses of RT (80 or 100 $\mathrm{mg} / \mathrm{kg}$ ) rescue mice from lethal experimental sepsis, 56 and $84 \%$, respectively (figure 3 ). These results support the hypothesis that RT provides a survival advantage in the presence of LPS-induced endotoxemia.

\section{Effect of RT on LPS-induced cytokine responses in vivo}

Several studies showed that the inflammatory mediators help the innate immune response but their overproduction results in acute phase endotoxemia that causing tissue injury, organ failure, shock, and even death ${ }^{12,13,14}$. The discovery of new agents capable of down-modulating the production of the inflammatory mediators that play key roles in the installation of sepsis is therefore of great 


\section{Soromou et al}

interest for the development of effective treatments. To assess the effects of RT, the levels of pro-inflammatory cytokines mechanistically linked to endotoxemia were measured in blood samples collected from mice $0,1.5,3$, 6 , and $12 \mathrm{~h}$ after LPS challenge. As results, levels of TNF- $\alpha$, IL-1b, and IL-6 production in RT-pre-treated (100 $\mathrm{mg} / \mathrm{Kg})$, LPS-challenged mice $(20 \mathrm{mg} / \mathrm{Kg})$ were consistently decreased as compared to that in mice that received the LPS alone (figure 4). The results from this investigation provide novel in vivo evidence showing that pretreatment with RT significantly regulated the overproduction of TNF- $\alpha$, interleukin IL-1, IL-6.
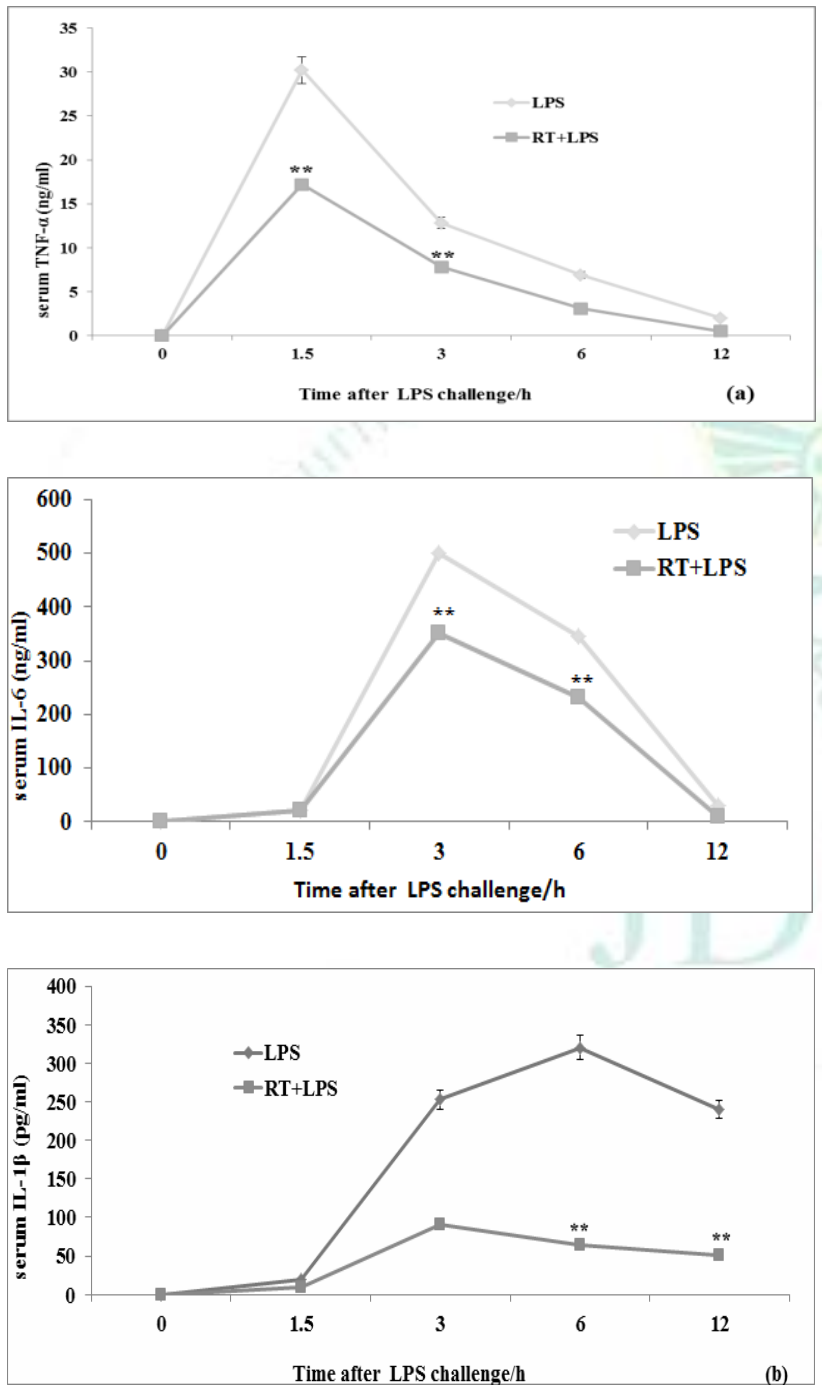

Figure 4: Effects of Rutin (RT) on the levels of pro-inflammatory cytokines mechanistically linked to endotoxemia. Mice were injected IP with RT $1 \mathrm{~h}$ before challenge with the LPS $(20 \mathrm{mg} / \mathrm{kg})$ and the blood samples were collected from mice $0,1.5,3,6$, and $12 \mathrm{~h}$ after LPS challenge. The serum levels of inflammatory cytokines were measured using ELISA. $* * p<0.01$ versus LPS-only group.
Journal of Drug Delivery \& Therapeutics. 2018; 8(1):108-113

\section{DISCUSSION}

Rutin (RT), a citrus flavonoid is known to possess multispectrum pharmacological benefits. The current study is the first to demonstrate that administration of RT can protect mice from LPS-induced death. The promising effects of RT administration included i) prevented mortality in mice injected with a lethal dose of LPS, ii) reduced host-derived proinflammatory cytokines.

LPS, a major cell wall component of gram-negative bacterial organisms; it mediates many of the pathophysiologic events in sepsis by stimulating the release of circulating proinflammatory cytokines. The sepsis syndrome is an acute systemic illness characterized by shock, coagulopathy, and multiorgan dysfunction, with death occurring in as many as $25-35 \%$ of patients with this syndrome 12,15 . Several studies showed that the pathogenesis of lethal sepsis remains obscure, but is associated with dysregulated production of inflammatory mediators. The early events of severe sepsis set in motion a cascade of events that contributes to the morbidity and mortality observed during the first few days of this syndrome ${ }^{16,17}$. Specifically, when compared with control group, we observed a significant increase in endotoxin-induced mortality in animals treated with LPS. Furthermore, the pre-administration of RT $(80 \mathrm{mg} / \mathrm{kg}$ or $100 \mathrm{mg} / \mathrm{kg})$ provided substantial protection via preventing, not only, the development of clinical manifestations of LPS administration (decreased activity, lethargy, diarrhea, piloerection, huddling), but also, the mortality against the lethal effects of LPS.

Macrophage activation by LPS results in the release of several inflammatory mediators, including proinflammatory cytokines such as tumor necrosis factor (TNF)- $\alpha$, interleukin (IL)-1, IL-6, IL-8, and IL-12. The exacerbated productions of these mediators by activated macrophages are the main cause of the consequences of septicemia, and may lead to disseminated intravascular coagulation, hypotension, tissue hypoxia, death and neutrophil extravasation to tissues ${ }^{18,19,20}$. (TNF)- $\alpha$ can induce vascular endothelial cells to express adhesion molecules, stimulating migration of PMNs, and therefore mediate the inflammatory changes in the multiple organs, resulting in PMN-dependent organ damage. It is shown that (TNF)- $\alpha$ may play a role in the progression of 


\section{Soromou et al}

multiple organ failure in septic shock, and there is an association between (TNF)- $\alpha$ and severity of shock and mortality 21,22 . The study demonstrated the in vivo protective effects of RT on production of these pro-inflammatory cytokines in LPS-challenged mice.

NF-KB is required for maximal transcription of numerous cytokines, including tumor necrosis factor a (TNF-a), interleukin $1 \mathrm{~b}$ (IL-1b), and interleukin 6 (IL-6); notably they participated in the early development of inflammation. (TNF)- $\alpha$ is the earliest and primary endogenous mediator of the process of an inflammatory reaction that can elicit the inflammatory cascade and cause damage to the vascular endothelial cells. TNF-a can also induce alveolar epithelial cells to produce other cellular factors and chemotactic, such as IL-6. IL-6 is one of the most common inflammatory cytokines ${ }^{23,24,25}$. IL-1 is a multifunctional cytokine that is responsible for various processes including host defense, inflammation, and response to injury. Many types of cells (predominantly macrophages) produce IL-1 after stimulation with viruses or bacterial components ${ }^{26}$. Therefore, inhibition of these proinflammatory mediators is a key issue in preventing endotoxic shock. In this experiment, we found that pretreatment with RT can effectively inhibit the production of TNF-a, IL- $1 \mathrm{~b}$ and IL-6 in LPS-induced endotoxemia suggesting that RT

\section{REFERENCES}

1. Kalantar-Zadeh K, Ikizler TA, Block G, Avram MM, Kopple JD. Malnutrition- inflammation complex syndrome in dialysis patients: causes and consequences. Am. J. Kidney Dis. 2003; 42:864-881.

2. Ren Y, Xie Y, Jiang G, Fan J, Yeung J, Li W, Tam PK, Savill J. Apoptotic cells protect mice against lipopolysaccharide-induced shock. J Immunol. 2008; 180(7):4978-85.

3. Namas R, Ghuma A, Hermus L, R Zamora, DO Okonkwo, TR Billiar, et al. The acute inflammatory response in trauma/hemorrhage and traumatic brain injury: Current state and emerging prospects. Libyan J. Med. 2009; 4:97-103.

4. Zhang FX, Kirschning CJ, Mancinelli R, Xu XP, Jin Y, Faure E, et al. Bacterial lipopolysaccharide activates nuclear factor- B through interleukin-1 signaling mediators in cultured human dermal endothelial cells and mononuclear phagocytes. J. Biol. Chem. 1999; 274: 7611-7614.
Journal of Drug Delivery \& Therapeutics. 2018; 8(1):108-113

could be a promising agent to prevent inflammatory diseases. As shown here, these findings indicate that the protective role of RT in endotoxemia may be attributable, at least in part, to modulation of pro-inflammatory cytokine production. The statement is consistent with the hypothesis that inflammation process can be mediated by pro-inflammatory mediators, including tumor necrosis factor (TNF)- $\alpha$, interleukin (IL)-1, IL-6, interferon (IFN)- $\gamma$, IL-12, IL-18, nitric oxide, and cell adhesion molecules. Inflammation and depression are closely inter-related; inflammation induces symptoms of depression and, conversely, depressed mood and stress favor an inflammatory phenotype. Anxiety and depression often appear together in the clinical population, as well as, fever, lethargy, hypophagia, anhedonia and impaired cognitive function ${ }^{27}$. The results found here may have a non-negligible effect when considering the consequences of the inflammatory mediators in mice.

\section{CONCLUSION}

In conclusion, this study provides evidence for the in vivo effects of RT on lipopolysaccharide-induced endotoxemia. This observation may be in future study a rationale for exploring the therapeutic potential of RT against other inflammatory pathologies.

5. Van der Watt E, Pretorius JC. "Purification and identification of active antibacterial components in Carpobrotusedulis L." Journal of Ethnopharmacology. 2001; 76 (1):87-91.

6. Kurisawa M, Chung JE, Uyama H, Kobayashi S. Enzymatic synthesis and antioxidant properties of poly (rutin). Biomacromolecules 2003; 4:1394-1399

7. Choi SJ, Lee SN, Kim K, Joo da H, Shin S, Lee J, et al. Biological effects of rutin on skin aging. Int J Mol Med. 2016; 38 (1):357-63.

8. Lu N, Ding Y, Yang Z, Gao P. Effects of rutin on the redox reactions of hemoglobin International Journal of Biological Macromolecules 2016, 89:175-180

9. The Natural Health Benefits of Rutin https://jonbarron.org/herbal-library/nutraceuticals/rutin

10. Sharma S, Ali A, Ali J, Sahni JK, Baboota S. Rutin: therapeutic potential and recent advances in drug delivery. Expert Opin Investig Drugs. 2013; 22(8):1063-79. 


\section{Soromou et al}

11. Ueno T, Ikeda T, Ikeda K, Taniuchi H, Suda S, Yeung MY, Matsuno N.. HMGB-1 as a useful prognostic biomarker in sepsis-induced organ failure in patients undergoing PMX-DHP J Surg Res 2011;171:183e90

12. Bone RC: The sepsis syndrome: Definition and general approach to management. Clin Chest Med 1996, 17:175-181.

13. Astiz ME, Rackow EC: Septic shock. Lancet 1998, 351:1501-1505.

14. Fairweather D, Rose NR: Inflammatory heart disease: a role for cytokines. Lupus 2005; 14:646-651.

15. Parrillo JE, Parker MM, Nathanson C, Suffredini AF, Danner RL, Cunnion RE, et al. Septic shock in humans. Advances in the understanding of pathogenesis, cardiovascular dysfunction, and therapy. Ann. Intern. Med. 1990; 113:227-242.

16. Cohen J. The immunopathogenesis of sepsis. Nature 2002; 420:885-891.

17. Benjamim CF, Hogaboam CM, Kunkel SL. The chronic consequences of severe sepsis. J. Leukocyte Biol. 2004; 75:408-412.

18. Soares MBP, Bellintani MC, Ribeiro IM, Tomassini TCB, Santos RR. Inhibition of macrophage activation and lipopolysaccaride-induced death by seco-steroids purified from Physalis angulata L. Eur J Pharmacol 2003; 459:107-12.

19. Tsiotou AG, Sakorafas GH, Anagnostopoulos G, Bramis J. Septic shock; current pathogenic concepts from a clinical perspective. Med Sci Monit 2005; 11:76-85.
Journal of Drug Delivery \& Therapeutics. 2018; 8(1):108-113

20. Lamontagne F, Meade M, Ondiveeran HK, Lesur O, Robichaud AR. Nitric oxide donors in sepsis: a systematic review of clinical and in vivo preclinical data. Shock 2008; 30:653-9.

21. Rios-Santos F, Benjamim CF, Zavery D, Ferreira SH, Cunha Fde Q. A critical role of leukotriene B4 in neutrophil migration to infectious focus in cecal ligaton and puncture sepsis. Shock 2003; 19: 61-65.

22. Enomoto N, Takei Y, Hirose M, Kitamura T, Ikejima K, Sato N. Protective effect of thalidomide on endotoxin-induced liver injury. Alcohol Clin. Exp. Res. 2003; 27: 2S-6S.

23. Bhatia M, Moochhala S. Role of inflammatory mediators in the pathophysiology of acute respiratory distress syndrome. J Pathol 2004; 202:145-156.

24. Hodge DR, Hurt EM, Farrar WL. The role of IL-6 and STAT3 in inflammation and cancer. Eur J Cancer 2005; 41:2502-2512.

25. Giebelen IA, van Westerloo DJ, LaRosa GJ, de Vos AF, van der Poll T. Local stimulation of alpha7 cholinergic receptors inhibits LPS-induced TNF-alpha release in the mouse lung. Shock 2007; 28:700-703.

26. Kielian T, McMahon M, Bearden ED., Baldwin AC, Drew PD, Esen N.S. aureus-dependent microglial activation is selectively attenuated by the cyclopentenone prostaglandin 15-deoxy- $\Delta$ 12,14- prostaglandin J2 (15d-PGJ2). J Neurochem. 2004 Sep; 90(5): 1163-1172.

27. Remus JL, Dantzer R. Inflammation Models of Depression in Rodents: Relevance to Psychotropic Drug Discovery. Int J Neuropsychopharmacol. 2016; 19(9): pyw028. 